amount of information collected by the authors about those names that figure in the text, nor is it only concerning surgeons who practised in Britain that the accuracy of the information can be vouched for from personal knowledge: the memoirs dealing with surgeons who practised in the Commonwealth countries furnish a wondrously accurate account and recall to me happy memories of lost friends.

Memory has been said to be an inspiration and incentive to those who labour in similar causes to-day : the perusal of the biographical notes in this volume cannot fail to be of profound interest and perchance inspiration to present-day surgeons and to others outside the surgical profession who find distraction in the stories of those who loyally and devotedly pursue "Quae prosunt omnibus artes". GORDON GORdON-TAYLOR

\section{DETERMINATION OF ADRENOCORTICAL STEROIDS}

Memoirs of the Society for Endocrinology

No. 2: The Determination of Adrenocortical Steroids and their Metabolites. (Proceedings of a conference held by the Society for Endocrinology, at the Medical Society of London, on 21 May, 1953.) Edited by P. Eckstein and S. Zuckerman. Pp. vii +92. (London: Dennis Dobson, Ltd., 1953.) 12s. 6d. net.

$\mathrm{T}$ HE second memoir of the Society for Endocrinology deals with factors influencing the estimation of adrenocortical steroids by means of their formaldehydogenic properties, with applications of paper chromatographic methods to adrenocortical steroid assays, with the use of sodium bismuthate to convert certain 17-hydroxycorticosteroids into 17-ketosteroids and with improved methods for the extraction of steroid conjugates from urine. In addition, the detection of a previously unidentified adrenal hormone is reported, and a study of the dehydroepiandrosterone output in adrenal virilism presented.

In the first two communications the formaldehyderetaining properties of urinary extracts are described, a method for overcoming this obstacle to analysis introduced, and a study of the excretion of acidlabile and acid-stable formaldehydogenic steroids, as measured by this improved technique, reported.

Three of the communications are primarily devoted to methods of paper chromatographic analysis. In these the importance of tetrahydrocortisone as a metabolic product the excretion of which reflects the intensity of adrenocortical steroid metabolism is emphasized, and semi-quantitative developments of the paper chromatographic methods described. A useful account of some recent developments of technique in this field is included.

The use of sodium bismuthate in the estimation of 17-ketogenic steroids is described. 'This technique should prove of great value in that it avoids the large and variable losses inherent in those methods of estimation of the 17-hydroxycorticosteroids which require preliminary acid hydrolysis followed by extraction and estimation of formaldehydogenic or reducing properties. Improved methods are given for the quantitative extraction of steroid glucuronides and sulphates.

The isolation of weighable amounts of a new adrenal hormone 'electrocortin' is described in a communication which undoubtedly constitutes an important advance in the biochemistry of the adrenal cortex. This steroid has an activity some ninety times that of deoxycorticosterone. Indications of its chemical structure have already been obtained.

A method is given for the difficult estimation of 17-hydroxycorticosteroids in plasma, based upon separation on a magnesium trisilicate column and colour development with a phenylhydrazine-sulphuric acid mixture. Measurements of the output of dehydroepiandrosterone and related substances in the urine of patients suffering from adrenal virilism are reported. Such cases appear to be separable into two distinct groups upon the basis of the levels of urinary excretion of 17-ketosteroids and of substances which are chromogenic with the phenylhydrazine - sulphuric acid technique.

The discussions which follow the communications and conclude the sessions materially add to the interest of this volume, which will be valuable alike to the research worker interested in the adrenocortical steroids and to those who follow the rapid developments in this field with the view of their application to clinical problems.

N. R. LAWRIE

\section{THEORY OF SYNTHETIC POLYMERS}

Fundamental Principles of Polymerization

Rubbers, Plastics and Fibers. By Dr. G. F. D'Alelio. Pp. $x+517$. (New York: John Wiley and Sons, Inc.; London: Chapman and Hall, Ltd., 1952.) $80 s$. net.

$7 \mathrm{HE}$ number of volumes on the fundamentals of polymers and polymerization is increasing rapidly. Each is usually addressed to a defined reader, for the subject is not only of purely academic interest but is also important for those who have to deal in the industrial field with plastics, rubbers and synthetic fibres. The author is well known for his practical manuals on the preparation of synthetic polymers, and this volume, being theoretical, is complementary to the other books. It is addressed to those in industry who have to deal with the more fundamental aspects of polymers, and not so much to a physical chemist interested in the development of any particular branch of physical chemistry to polymer systems themselves. The arrangement of the book is somewhat unusual ; but it is in conformity with the author's intentions in regard to his potential readers.

First of all there is a very general chapter, its object being to show the place that polymers occupy in relation to other kinds of matter, and the further sub-division of high polymers into plastics, rubber's and fibres. Then follows a chapter dealing in a descriptive way with polymerization reactions in general. Rather strangely the next chapter is devoted to a discussion of the evidence for the existence of macromolecules, a matter which was of interest but is now to a large extent of historical importance only. The properties of polymers in general are treated in one long comprehensive chapter in which the structure of the polymer molecule and the behaviour of the polymer substance are discussed in close relationship to each other. Having thus dealt with matters in general, the author then proceeds in the remaining two-thirds of the volume to examine in detail the processes of polymerization. Polycondensation and 